\title{
A!
}

This is an electronic reprint of the original article.

This reprint may differ from the original in pagination and typographic detail.

Kyrö, Riikka; Jylhä, Tuuli; Peltokorpi, Antti

\section{Embodying circularity through usable relocatable modular buildings}

\section{Published in:}

Facilities

DOI:

10.1108/F-12-2017-0129

Published: 04/02/2019

Document Version

Peer reviewed version

Please cite the original version:

Kyrö, R., Jylhä, T., \& Peltokorpi, A. (2019). Embodying circularity through usable relocatable modular buildings.

Facilities, 37(1-2), 75-90. https://doi.org/10.1108/F-12-2017-0129

This material is protected by copyright and other intellectual property rights, and duplication or sale of all or part of any of the repository collections is not permitted, except that material may be duplicated by you for your research use or educational purposes in electronic or print form. You must obtain permission for any other use. Electronic or print copies may not be offered, whether for sale or otherwise to anyone who is not an authorised user. 


\title{
Embodying circularity through usable relocatable modular buildings
}

\begin{abstract}
Purpose: Global megatrends such as urbanization and ageing of the population result in fast-paced demographic changes, which pose different types of challenges for different regions. While many rural municipalities bear the burden of under-utilized buildings, cities are in a hurry to develop new ones to meet new space demands. The purpose of this research is to assess the potential of relocatable modular buildings to address these challenges, following the principles of circular economy, while at the same time offering usability.

Design/methodology/approach: This multiple case study explores existing relocatable modular healthcare buildings in Finland. The case buildings host hospital support functions, imaging services, a healthcare centre, and a care home. The primary data comprises 21 semi-structured interviews and observation during factory and site visits.

Findings: Based on the findings, relocatable modular buildings have many benefits, and provide a viable option for cities and municipalities struggling to meet their fluctuating space demands. Some challenges were also identified, mainly derived from the dimensional restrictions of the modules.

Originality/value: This research contributes to the emerging body of knowledge on circular economy in the built environment. More specifically, the research provides a very concrete example of circularity, and details a framework for usable and relocatable modular buildings. In conclusion, relocatable modular buildings could solve the challenges posed by quickly changing demographics in different types of regions, and deliver both usability and circularity.
\end{abstract}

Keywords: Circular economy, Building, Built Environment, Modular, Relocatable, Usability Research paper

\section{Introduction}

Due to megatrends such as urbanization and ageing of the population, different types of regions are facing different types of demographic challenges. From the perspective of the built environment, these fast-paced demographic changes mean that while many rural regions bear the burden of under-utilized buildings, growing cities are developing new ones at an overwhelming rate. Both situations are putting a lot of pressure on the environment, in the form of energy and 
resource use, and related greenhouse gas emissions. Modular buildings (Jonsson \& Rudberg 2015; Peltokorpi et al. 2017), which can be relocated from one site to another based on need, offer one potential solution.

One has to bear in mind, though, that the idea of recycling buildings challenges the paradigm of ownership. People tend to appreciate new products over second-hand, and ownership over lending (Pomponi \& Moncaster (2017). In recent years, however, sharing economy has gained popularity and people maybe be more open for a new ideal of access over ownership. Sharing would be particularly beneficial in activities with a high emission intensity, such as housing (AlaMantila et al. 2016). In line with this thinking, Brinko et al. (2015) and Brinko \& Nielsen (2017) establish a typology for municipal shared facilities. The typology outlines the different types of sharing based on what, why, how and who is sharing (Brinko \& Nielsen 2017). Tukker (2015) calls this type of sharing 'product sharing', which is a sub-category of a user-oriented service. While the focus is still on the product (in this case, on a building), the business model is about leasing, in line with the principles of the sharing economy (Tukker 2015). Offering modular buildings as a service, without ownership, is in line with both sharing and circular economies.

In addition to representing sharing economy, relocatable buildings are also a prime example of circular economy. Based on their extensive literature review, Geissdoerfer et al. (2017) define circular economy as a regenerative closed loop system, which can be achieved e.g. through appropriate design, maintenance, refurbishing or reuse. This definition fits modular relocatable buildings well. Furthermore, commercial actors typically define some key circular economy elements, including resource efficiency; preserving and extending what is already made, designing for the future, rethinking the business model; collaboration, and; use of technology and digitalization (Circle Economy 2017). Most of these elements are present in the modular building solution. 
Research on circular economy in the built environment is still in its infancy. Pomponi and Mancaster (2017) conducted a literature review, and suggested that circular economy should be examined on a macro, meso and micro level, where macro refers to city level, meso to the building level and micro to the building material level. Different 'Eco City' trials have been ongoing for years, and building materials often exploit post-consumer content such as sludge (Smol et al. 2015). However, the so called 'meso' level, the level of an individual building, has previously been largely overlooked in circular economy.

Pomponi and Mancaster (2017) further conclude that while the technological and even ecological dimensions of the circular economy are quite established, there are still many issues with the social, political, and behavioural challenges to overcome. Similarly, Brinko et al. (2015) argue that the paradigm of ownership should change toward sharing, and shared facilities have a lot of potential, particularly in municipal real estate portfolios. The research at hand also focuses on the public sector, and the potential of the relocatable leased buildings in that context.

In addition to the challenges posed by the paradigm of ownership, modular buildings suffer from a poor reputation when it comes to aesthetic architectural quality. Based on previous literature, a monotonous design and rigidness results from factory manufacturing and the transport of the modules (Da Rocha et al. 2015; Edelman et al. 2016). Prefabricated modules are indeed restricted in height, width, and length, and bearing capacity (Doran and Giannakis 2011; Edelman et al. 2016), which set limits to architectural design. On the other hand, as Brand (1994) suggested already two decades ago, a simple design allows for adaptability during the building's lifecycle, and should therefore be valued over architectural quality. In light of these known characteristics of modular buildings, this research focuses on the potential of relocatable buildings to deliver usability. Usability here is defined as in ISO Standard 9241-11:1998 as the potential of the building to meet the needs of the specific building users in terms of effectiveness, efficiency and satisfaction. The definition carries with it the context, time and situation of use, not only the product as such. (ISO 9241-11:1998)

In summary, the aim of the study is to provide a framework for a modular relocatable building that could deliver both circularity and usability. The study examines one producer of relocatable modular buildings, utilizing three case sites in Finland. In Finland, interest in modular and relocatable buildings has increased significantly during the 2010s especially in the public 
sector. Particurlarly the school and healthcare sector have utilized temporary modular solutions, mostly due to booming renovation needs, migration between regions and acute moisture problems in existing facilities. The case building functions comprise hospital support functions, imaging services, a healthcare centre and a care home. The primary data included semi-structured interviews, whereas additional data comprises site visits and observation, as well as written documents.

The remainder of the paper is structured, as follows. Section 2 details the methods and data utilized. Section 3 introduces the results of the literature review on forms the initial framework on modular relocatable buildings. Section 4 develops the framework further with findings from producer, client and user interviews. Section 5 then introduces the proposed final framework for relocatable modular buildings. Finally, in Sections 6 and 7 findings are discussed and conclusions are presented.

\section{Material and methods}

Research fields, which are not well-established, benefit from explorative, qualitative research approaches (Edmondson \& McManus 2007). Circular economy in general, and circularity within the built environment in particular, are emerging fields of study. This makes in-depth case studies of a limited number of cases an appropriate approach. Semi-structured interviews with key stakeholders along with onsite observation, are suitable data collection methods.

The research was conducted in four phases, starting with a focused literature review, described by Levy and Ellis (2006) as the "lens". The lens is formed in order to guide readers to the appropriate context. In this case, the lens type literature review was utilized to form an initial framework for relocatable modular buildings. The scientific articles were selected from a project database at Aalto University with 71 scientific articles on modular buildings and prefabrication. The selection of the 13 articles was based on relevance, focusing on the benefits and challenges of modular building. The initial framework is introduced in the following Section 3 .

The research continued with a factory visit and interviews with a selected relocatable modular building producer, and consequent revision of the framework. A user perspective was embedded with the help of case studies, and a final framework constructed as a synthesis of these. Figure 1 illustrates the research design, also detailing the data utilised in this research. 


\section{FIGURE 1}

A purposive sampling strategy was utilized for case selection. The relocatable modular building producer offered to provide access to a number of projects they had been involved with, and were able to provide the contact details for the sites. In the choice of the cases, variation in terms of type and location was sought to create a heterogeneous sample. Heterogeneous or maximum variation sampling is helpful in identifying patterns which are of particular interest and value (Saunders et al. 2007). Subsequently, three different types of healthcare sites from Finland were chosen, that all fulfilled the following selection criteria:

1. Cases represent relocatable modular buildings in different types of healthcare sites, functions and user groups

2. Cases represent different client organizations around Finland

3. Case buildings are at different phases of their lifecycle (at the time of research)

The first site (Case A) is located on a hospital campus in Southern Finland. The modular buildings were delivered to the campus in 2012 and comprise imaging facilities and offices. The second site (Case B) is a care home in the capital city Helsinki. The modular buildings date back to the early 2000s and have been multiple different uses. The third site (Case C) is a healthcare center in Eastern Finland. The healthcare center was relocated to the site in 2015. Some key characteristics of the three sites are listed in Table 1.

\section{TABLE 1}

\subsection{Data collection and analysis}

The main data source for the study comprises semi-structured interviews with 21 informants. First, four key representatives of a producer of modular buildings in Finland (hereinafter, 'the Producer') were interviewed with the purpose of strengthening the theoretical background with regard to relocatable modular buildings, of which only limited literature exists. The Producer interviews focused on basic information about the modular solution, its usability for

different purposes, and possibilities for participatory methods in the design phase. All key personnel of the Producer, including the $\mathrm{CEO}$, the $\mathrm{COO}$, the lead designer and the head of sales 
were interviewed. The Producer pre-fabricates and leases relocatable modular buildings for municipalities and other public actors in Finland and Sweden. Most of the modular buildings produced annually replace older buildings from the 1960-70s with indoor air quality issues. The calculated lifecycle of the modular buildings is 20 years, even though they are generally expected to sustain 25-30 years. Currently, around a quarter of all the Producer's modular buildings are in their second or third location and use.

The majority of the informants (17) are Clients or Users from three case sites, focusing the study strongly on user perceptions and experiences. It was considered important to interview at least one informant representing a client role (architect, municipal real estate manager) for each case. However, as the focus was on end-user experiences, most informans represent the user role. A summary of the informants is presented in Table 2, and a more detailed list is found as Appendix I to this paper.

The interviews comprised questions about the usability of the modular buildings and also other usability related questions such as user participation in the design phase and workplace comfort and satisfaction.

Of the 21 interviews, 20 were conducted face-to-face, recorded and transcribed. The last interview was conducted as a conference call, and two researchers made notes during the call. The interviews ranged between $33 \mathrm{~min}$ and $90 \mathrm{~min}$, and 3-4 researchers were present at each interview.

\section{TABLE 2}

Observations during the factory and site visits comprise another important data source. The observations were made by several researchers during site walks that lasted 30-60 mins. During the site walks, the researchers were able to reflect, verify and deepen the content of the interviews. The researchers combined their notes and observations into a common project database including photos and other additional material, such as brochures.

In the qualitative content analysis, benefits and challenges of relocatable modular buildings were searched from the interview transcripts and documented observations. Instead of quantifying the content, as it is often proposed (e.g., Sandelowski 2000, Bryman 2012), content analysis here follows a so called directed approach presented by Hsieh and Shannon (2005). This approach to 
qualitative content analysis utilises theory as a starting point to find initial codes but also allows to form new codes based on the data (Hsieh and Shannon, 2005). In other words, theory has a deductive role in the analysis (Potter and Levine-Donnerstein, 1999). Due to the deductive nature, the direct approach to qualitative content analysis is typically used to extend or validate existing theoretical frameworks (Hsieh and Shannon, 2005). In the research at hand, the relocatable modular buildings theory is extended by studying the benefits and challenges of these buildings from the producer, client and user perspectives.

\section{Constructing an initial framework for modular buildings}

The initial framework is based on the characteristics identified in previous literature on modular construction, as well as a few available studies on relocatable buildings. The general benefits and challenges of modularity have been explored in several previous studies (Pasquire and Gibb 2002; Jaillon and Poon 2010; Doran and Giannakis 2011; Choi and Song 2014; Da Rocha et al. 2015; Nahmens and Bindroo 2011). Loose coupling between modules enables their prefabrication which saves considerable amount of time and cost in onsite construction and assembly activities (Jaillon and Poon 2010; Nahmens and Bindroo 2011; Pasquire and Gibb 2002). Other commonly listed advantages of prefabrication include better quality control, resource efficiency, improved health and safety, more efficient labour and management, and less disruption in the construction phase (Jaillon and Poon 2010; Pasquire and Gibb 2002). Gosling (2016) also notes the better quality achieved through standard solutions as a benefit of modular prefabrication. Nahmens and Bindroo (2011) report that industrialized construction reduces labour cost on the one hand, and improves employee satisfaction and quality on the other.

Other scholars have focused on the sustainability benefits of prefabrication. Modularity reportedly supports sustainability through reducing construction waste, reducing employee

commuting and associated greenhouse gases, creating less construction site noise and other disruption, as well as improving insulation and therefore energy efficiency and acoustic quality (Nahmens and Ikuma 2012; Lawson et al. 2012; Quale et al. 2012).

One clear challenge discussed in earlier literature is related to the ability to customize mass produced buildings, which are often have a rigid design (Da Rocha et al. 2015). Additional challenges are imposed by dimensional restrictions (height, volume, weight) due to prefabrication on the one hand, and road transport on the other (Doran and Giannakis 2011). Several studies 
indicate a large initial investment required from the producer (Gosling et al. 2016; Jaillon and Poon 2010; Choi \& Song 2015), which may be seen as a disadvantage. However, for an established producer with existing production facilities, this does not present an issue.

Modular buildings are volumetric building modules which alone or when connected to each other form the actual building (Peltokorpi et al. 2017). In addition to the general literature on modular buildings and their prefabrication, two previous studies from Finland address the business model of leasing relocatable modular buildings. These two studies find modular buildings to be inherently adaptable as they are leased for a certain period and may be reused in same or new combination of modular buildings in another location (Edelman et al. 2016; Vihola et al. 2016). Adaptability is an important property in buildings, as it is a way to avoid early obsolescence, and therefore promote sustainability (Arge, 2005). Adaptability is often categorised in three levels. Generality is the lightest form of adaptability and refers to changes managed through nondestructive procedures with minimal work inside the facility. It can also mean a multifunctional use between wider user groups based on versatile and standardized room layouts and fittings (Carthey et al. 2011; Pati et al. 2008). Arge (2005) uses the term elasticity for the ability of a building to be extended with changing space demands. Further, Arge (2005) states that flexibility is the possibility to make minor modifications to a building, such as adding wall partitions.

In relation to adaptability, Edelman et al. (2016) identify many benefits related to leasing, where the producer obtains risk for any repair of maintenance. Vihola et al. (2016), focus on the lifecycle costing of the modular buildings, and find the leasing alternative to be beneficial to the client in case the facility is operational less than 40 years. Finally, Edelman et al. (2016) notes the poor image associated with temporary nature of the relocatable modular buildings is often a concern to the clients.

Table 2 summarizes the benefits and challenges based on previous research on prefabricated building modules.

\section{TABLE 3}

In this initial framework, key benefits comprise the rapidity in delivering and assembling the modules, quality derived from standardization, as well as sustainability, mainly derived from resource efficiency. Furthermore, the leasing model enables adaptability, specifically, the

possibility to add or remove modules based on contemporary space needs. Due to the leasing 
model, there is no need for any significant initial capital investment, which removes the burden of ownership. The key challenges comprise rigid design due to the mass-production, and dimensional restrictions due to factory prefabrication and road transport. Moreover, prefabricated modular buildings may also suffer from poor image.

\section{Elaborated framework for relocatable modular buildings}

The findings presented in this section complement the findings of the literature review by introducing results from 4 interviews with producers of relocatable modular buildings (Producer interviews 1-4 in Appendix 1), and from 17 interviews with clients and users from the three case locations (Client interviews 1-4 and User interviews 1-13 in Appendix 1), as well as observations made during a factory and site visits. Next, the findings are presented following the structure of the interviews, supported by direct quotes from the informants.

\subsection{Producer perspective}

\subsubsection{Benefits of relocatable modular buildings from the producer perspective}

Modular buildings may be easily and rapidly prefabricated, transported and assembled on existing school, hospital, or other sites based on demand. Rapidity is often the most appreciated feature of the relocatable modular buildings. The throughput time to produce a module in the factory is around 9-12 days, and assembly typically takes three weeks. Only the foundation works have to be performed onsite: "The user will get the space really quickly [...] At best, or maybe worst from the designer perspective, the design process may be only a month."(Producer 3)

The modules are hauled to the site and connected with cranes or hoists. The fully equipped, load-bearing and volumetric modules include all structural elements, doors, windows and finishes, even cabinets and other fittings. Whenever possible, the Producer offers the Client existing modules, either transferred from another site or new ones that are ready in stock at the factory.

With regard to quality, the findings support existing literature on that prefabricated modules are of high quality due to the quality control in factories and e.g. no exposure to weather conditions. Especially the indoor comfort was considered a competitive advantage of the modular buildings: "The modules are light, they have new [building system] technology, they are warm, there is no draft, there is no mildew." (Producer 1) 
The Producer's business model is based on leasing, rather than selling the modular buildings. The lease period for the buildings is 3-7 years, making the solution suitable for shorterterm use, and allowing for reacting to changes in space needs. Adaptability is a key benefit in the business model of the producer, as the modular buildings are able to provide the right amount of space in the right place at the right time. When space is no longer needed, the module(s) can be hauled off to another location. Similarly, if space demand increases as a result of demographic changes, one or more modules may be added to the modular building: "[We help] in those fluctuating circumstances when the client does not know what will happen tomorrow or the day after tomorrow." (Producer 4)

The adaptable solution is in line with the idea of shared spaces. Furthermore, the Producer representative also highlighted the multifunctionality resulting from standardized solutions and connections between the modules: "In terms of functionality, we produce a lot of modules so we know what spaces should be next to which space, so that the interior space is in the right order."(Producer 1)

Furthermore, the producers wanted to emphasize the low risk associated with a leased facility. The investment risk to municipalities is significantly reduced as there is no initial capital cost for the leased modules, and the producer bears responsibility of any major maintenance and retrofitting: "It is sort of our core product, or core competence, that we specifically lease the buildings. That we carry the risk of ownership for the client."(Producer 2)

Then, at the end of the lease period, the building and its parts may be leased to the next customer for another purpose, and relocated. The possibility to located the modular buildings within urban structure and utilizing existing infrastructure or even existing buildings, was also considered one of the main benefits: "...We have used the satellite model in many locations and effectively. So there is a small corridor and you do not have to touch the structure of the existing building at all." (Producer 1)

\subsubsection{Challenges of relocatable modular buildings from the producer perspective}

In the interviews, a group of challenges were also reported. The challenges may all grouped under the umbrella term 'Limited customization', which may be derived from either factory conditions, preparing for the reuse of the modules, lifecycle costing, or schedule. As one informant 
stated: "The biggest challenge are the technical limitations we have [...] so that the client's and user's wishes are fulfilled in a way that they accept the compromises." (Producer 3)

Due to the leasing business model, the reuse of any module in another location has to always be considered, and therefore high-level customization may not be economically feasible: “We can do a lot in terms of customization, but then the lease period has to be longer." (Producer 4)

In many instances, the schedule might be too tight to engage the users in the design or does not leave room for customization: "A really large portion [of orders] are ones, when there is no way to use any extra time on changes." (Producer 3). In other words, modularity alone does not guarantee quick delivery. If the end-user requires customization, the delivery process will become

longer. Some limitations cannot be overcome even if the schedule would allow: "These types of really large lobbies that might be two or three stories high, it is really challenging to produce those, in some cases it is impossible with our technology." (Producer 2)

\subsection{Client and User perspective}

\subsubsection{Benefits of relocatable modular buildings from the client and user perspectives}

Rapidity is one key reason to consider modular buildings: "Of course you have to do the ground works, so they are not necessarily always that much cheaper [than traditional buildings], but they are faster to implement and move forward [in the administration] " (Client 3, Case B).

The high quality of prefabricated modular buildings found in the literature and producer interviews was confirmed in the user interviews and site visits. The amount of daylight, derived from the narrow structure of the modular buildings, was complimented in all cases, and views particularly in Case B: "I think the nature is so great, many residents feel calm there, at the glass door, sitting by the door and seeing the birds at the bird feeder in the yard." (User 13, Case B)

Based on the user interviews and observation during site visits, indoor comfort was one of the most essential benefits: "These are one of our best facilities because we have cooling, and ventilation is working as it should." (Client 1, Case A)

Client 4 in Case $\mathrm{C}$ managed a portfolio of several different locations, and mentioned that the modular buildings were the only ones with no complaints about indoor comfort from Users. 
Adaptability was often considered in a broader, hospital district scale. In Case A, the plan was to add modules as the hospital campus retrofitting proceeded: "You could add these modules, to bring more floors, what a benefit that would be, for example to healthcare districts. "(User 4, Case A)

Multifunctionality and standardized solutions were also noted in the user interviews and exemplified during the site visits. For example in Case A, every room had the same equipment in the same place, making it possible for any nurse of doctor to operate in the room. This was said to make medical work a lot easier: "Everything is thought through, using lean principles, so that there is everything in every cabinet."(User 2, Case A)

Interestingly, the end-users did not mention resource-efficiency, or any other sustainability related benefits, that the modular buildings are generally expected to deliver. This could be because energy use is not visible to building users, or not perceived as of primary concern in the healthcare field.

\subsubsection{Challenges of relocatable modular buildings from the client and user perspectives}

Customization of the modular buildings is always possible within the technical (height, depth, bearing capacity) limits of the modules. However, the bearing functionality and electricity capacity are limited, which limits the use of e.g. heavy hospital equipment as was noted in the user interviews: "In practice, a CT scan weighs a few hundred kilos, that might be possible [...] if we planned that, but there would need to be led walls all around."(User 3, Case A)

The dimensional restrictions from the factory prefabrication and road transport place limits on the type of functions that may be placed inside the relocatable buildings. The size of the modules is limited by both factory capacity and regulations for road transport. The height and width have to be adjusted to the prefabrication conditions inside the factory. Moreover, for Case A, the standard size of the modules created an unusual problem, where the delivered modular building was actually too large: "The current facilities are excellent for the use, but they are way too big. If we knew there was going to be so much space we would have divided the module into three, instead of two rooms. But is has something to do with the [dimensions of the] modular solution." (User 3, Case A) The oversized facility reduced space-efficiency, creating extra costs.

Customization is further limited by the rapid timetables typical for the modular buildings. The procurement of temporary facilities is typically under strict time pressure, and there is no time 
to use participatory methods. Some of the users saw this as a problem: "Naturally, my supervisor has been involved in the design phase, but maybe it would be better to involve the actual person working in that space, so you could say there should have been more user engagement in the design of the layout of spaces." (User 13, Case C)

Based on the Client interviews, customization is also a question of lifecycle costing. The costs of customization are inflicted on the Client, and with heavy customization, benefits related to the leasing model and low risk of ownership would become diluted: "Well I think you need to consider how long it will be in use, there is no point, if it is like 5 years, does it make sense to invest." (Client 1, Case A)

As for poor architectural quality, the interviewed Users did not see any problems: "Well this is actually a finished space, they have even thought about employee satisfaction and comfort from an employee's perspective." (User 7, Case C) This is a major finding as the dull design has previously been seen as an obstacle for the wider utilization of modular buildings.

Table 4 summarises the findings from the literature review, interviews, and observation during the factory and site visits.

\section{TABLE 4}

\section{Synthesis of findings}

A synthesis of the findings of the literature review and empirical data collection provides insight into how circularity and usability is achieved with modular buildings (Figure 2). Figure 2 presents the identified benefits and challenges, divided based on whether they are related to modularity and prefabrication, or to the relocatability derived from the leasing model. The findings suggest that modular buildings can be delivered quickly as ready-to-assemble modules, which results in minimal disruption onsite. The standardized solutions offer multifunctionality and high quality solutions, resulting in good indoor comfort, and allowing the users access to daylight and views. Owing to the leasing model and the temporary nature of the modular buildings, the modular buildings come without the burden of ownership, and may be located within existing urban structure or even on site. Furthermore, the modular buildings have high elasticity, i.e. modules may be added or removed based on changes in space needs. 
FIGURE 2

Figure 2 also illustrates whether these characteristics support usability, circularity, or both. It is worth noting that, some of key characteristics derived from the leasing model, such as the possibility to remove or add modules and locate them within existing urban structure and even onsite, also support the usability of the modular building. Similarly, the multifunctionality derived from standard modular solutions supports circularity.

No evidence was found to support that poor image or rigid design would negatively impact usability. Unfortunately, however, the dimensional restrictions due to factory manufacture and transportation seem to still limit the usability of the modular buildings. Moreover, a tight schedule as well as the need to reuse the modules somewhere else in the future may further limit customization, and as a result, trump usability.

\section{Discussion}

This study set out to examine the potential of relocatable modular buildings in delivering circularity and usability in the built environment. Based on the findings, leasing and reusing buildings were not found problematic by the Users. This supports Brinko et al. (2015) idea that, the paradigm of ownership is changing. Based on Tukker (2015) this type of sharing is product sharing, which is a sub-category of a user-oriented service. While the focus is still on the product (in this case, a building), the business model is about leasing, in line with the principles of the sharing economy.

While clearly situated on the 'meso' level (Pomponi \& Mancaster 2017), the relocatable modular buildings contribute to all levels the circular built environment, as they utilize existing urban structure and infrastructure, and are also resource efficient to manufacture due to factory prefabrication. The ability to relocate a building entirely represents the highest level of adaptability, the possibility to expand or decrease the size of existing buildings. The level is analogous to Brinko et al. (2017) typology of shared municipal spaces, characterized by serial sharing of core facilities owned by one owner who decides on who gets to share.

Coming back to the definitions of circular economy by Geissdoerfer et al. (2017), the modular relocatable buildings minimize resource use and close energy loops both through 
prefabrication and leasing, i.e. reusing the modules. Furthermore, of the commonly utilized seven circular economy elements (Circular Economy 2017), the relocatable, leased modular buildings comply with at least the following: resource efficiency, preserving and extending what is already made, designing for the future, and rethinking the business model. Based on the challenges related to the dimensional restrictions and customization, the elements that could be further enhanced include collaboration between stakeholders, use of technology and digitalization in the solution.

From the real estate portfolio management perspective, the most attractive characteristics of the modular buildings include the low risk associated with leasing, and the possibility to add or remove modules as needed. Good indoor comfort and energy efficiency, as well as the possibility to customize based on the planned function (school, day care, healthcare) would also be of interest to the municipal real estate manager. Modular buildings could well replace a portion of municipal facilities, making the building stock more adaptable to fast-paced demographic changes. As previous research on modular buildings reserves them a rather narrow role as a low customer adaptability and high productivity solution (Jonsson and Rudberg 2014; 2015), this research provides evidence that modular buildings can bring high customer adaptability if usability and circularity both in single modules and between modules at a building level are taken into account in design and lifecycle management.

The limitations of the study are typical to a qualitative study based on interviews. However, the different data sources provide data triangulation, while the presence of several researchers in the interviews and visits offer researcher triangulation. Validity is further increased through conducting data analysis collectively with the three authors of this paper. It should also be noted, that the study is not aiming at statistical generalisation, but rather provides analytical generalization and a novel concept for the nascent field of circular economy research within built environment on the building level.

\section{Conclusions}

Based on the findings it appears that the modular buildings face some of the same challenges as traditional buildings, namely, tight schedule in the design stage, which limits stakeholder communication and user participation in design. While the modular solutions are incredibly quick to assembly, if customization is needed, the delivery times inevitably become 
longer. In other words, modularity in itself is not able to deliver both a customized and a rapid solution. Customization, with the appropriate participatory methods, takes time, exactly like participatory design in traditional building projects.

How then, should these identified and confirmed challenges be addressed in the solution? Peltokorpi et al. (2017) discuss the active engagement of different stakeholders in the design phase to enhance the benefits of modularity. Previous research has also shown that standardization is an effective way to manage complex processes and by utilizing modularity, standardization can be achieved while still providing customization (Eissens-Van der Laan et al. 2016). Future research should address the lack of customization and ways to improve it without hindering circularity in relocatable modular buildings.

\section{Acknowledgements}

The authors wish to thank Dr Hylton Olivieri for allowing access to his systematic literature review of modular building. The authors also thank all 21 informants for their kind collaboration. This research was conducted as part of the research project Healing and Modular Healthcare Facilities, where the Producer is an industry partner. This allowed the researchers access to their production facilities and internal data. The research, however, was conducted independent of any third party.

\section{References}

Ala-Mantila, S. Ottelin, J. Heinonen, J. and Junnila, S. (2016). To each their own? The greenhouse gas impacts of intra-household sharing in different urban zones. Journal of Cleaner Production, 135, 356-367.

Arge, K. (2005),"Adaptable office buildings: theory and practice", Facilities, 23(3/4), 119 -127.

Brand, S. (1994) How buildings learn: What happens after they are built. Viking Penguin, New York.

Brinkø, R., Nielsen, S. B., \& Meel, J. Van. (2015). “Access over ownership - a typology of shared space", Facilities, 33(11/12) 736-751.

Brinkø, R. and Nielsen, S. B. (2017) "The characteristics to consider in municipal shared spaces", Journal of Facilities Management. DOI: http://dx.doi.org.10.1108/JFM-11-2016-0051

Bryman, A. (2015) Social Research Methods, $5^{\text {th }}$ edition, Oxford University Press, Italy. 
Circular Economy (2017) "Making Sense of the Circular Economy - the 7 Key Elements". Available online at: http://www.circle-economy.com/the-7-key-elements-of-the-circulareconomy

Choi, J. and Song, H. (2014), "Evaluation of the modular method for industrial plant construction projects", International Journal of Construction Management, 14(3), 171-180.

Doran, D. and Giannakis, M. (2011), "An examination of a modular supply chain: A construction sector perspective”, Supply Chain Management: An International Journal, 16(4), 260-270.

Edelman, H., Vihola, J., Laak, M. and Annila, P. (2016) "Resiliency of prefabricated daycares and schools: Finnish perspective to relocatable education facilities", International Journal of Strategic Property Management, 20(3), 316-327.

Edmondson, A.C., and Mcmanus, S. E. (2007) "Methodological fit in management field research", Academy of Management Review, 32(4), 1246-1264.

Eissens-Van der Laan, M., Broekhuis, M., van Offenbeek, M. and Ahaus, K., (2016) "Service decomposition: a conceptual analysis of modularizing services", International Journal of Operations \& Production Management, 36(3). 308-331.

Gosling, J., Pero, M., Schoenwitz, M., Towill, D. and Cigolini, R. (2016) "Defining and categorizing modules in building projects: An international perspective", Journal of Construction Engineering and Management, 04016062, 1-11.

Geissdoerfer, M.; Savaget, P.; Bocken, N. M. P.; Hultink, E. J. (2017). "The Circular Economy A new sustainability paradigm?", Journal of Cleaner Production. 143: 757-768.

Hofman, E., Voordijk, H. and Halman, J. (2009) "Matching supply networks to a modular product architecture in the house-building industry", Building Research and Information, 37(1), 3142.

Hsieh, H.-G. and Shannon, S.E. (2005) Three Approaches to Qualitative Content Analysis, Qualitative Health Research, 15(9), 1277-1288.

ISO (1998) "Ergonomic requirements for office work with visual display terminals (VDTs)". ISO Standard 9241-11:1998.

Jaillon, L. and Poon, C.S. (2010), "Design issues of using prefabrication in Hong Kong building construction", Construction Management and Economics, 28, 1025-1042. 
Jonsson, H. and Rudberg, M. (2015) "Production System Classification Matrix: Matching Product Standardization and Production-System Design", Journal of Construction Engineering and Management, 141(6), 1-10.

Jonsson, H. and Rudberg, M. (2014) "Classification of production systems for industrialized building: a production strategy perspective", Construction Management and Economics, 32:1-2, 53-69.

Lawson, R.M.; Ogden, R.G. and Bergin, R. (2012), “Application of modular construction in highrise buildings", Journal of Architectural Engineering, 18(2), 148-154.

Levy, Y. and Ellis, T. J. (2006) "A systems approach to Conduct an Effective Literature Review in Support of Information Systems Research”, Informing Science Journal, 9.

Nahmens, I. and Ikuma, L- H. (2012) "Effects of Lean Construction on Sustainability of Modular Homebuilding" Journal of Architectural Engineering, 18(2), 155-163.

Nahmens, I. and Vishal Bindroo, V. (2011) "Is Customization Fruitful in Industrialized Homebuilding Industry?” Journal of Construction Engineering Management, 137(12), 1027-1035.

Pasquire, C.L. and Gibb, A.G.F. (2002), "Considerations for assessing the benefits of standardisation and pre-assembly in construction", Journal of Financial Management of Property and Construction, 7(3), 151-161.

Peltokorpi, A., Olivier, H., Granja, A. D., Seppänen, O. (2017), "Categorizing modularization strategies to achieve objectives of buildings investment", Construction Management and Economics. DOI: http://dx.doi.org/10.1080/01446193.2017.1353119

Pomponi, F. and Doncaster, A. (2017). "Circular economy for the built environment: A research framework", Journal of Cleaner Production, 143, 710-618.

Potter, W.J and Levine-Donnerstein, D. (1999) Rethinking validity and reliability in content analysis, Journal of Applied Communication Research, 27(3), 258-284.

Da Rocha, C.G.; Formoso, C.T. and Tzortzopoulos, P. (2015), “Adopting product modularity in house building to support mass customization", Sustainability, 7, 4919-4937.

Sandelowski, M. (2000) Whatever Happened to Qualitative Description?, Research in Nursing and Health, Vol. 23 No. 4, pp. 334-340.

Saunders, M., Lewis, P., \& Thornhill, A. (2007). Research Methods for Business Students (4th ed.). Essex: Pearson Education Limited. 
Smol, M., Kulczycka, J. Henclik, A., Gorazda, K. and Wzorek, Z. (2015) "The possible use of sewage sludge ash (SSA) in the construction industry as a way towards a circular economy." Journal of Cleaner Production, 95:45-54.

Tukker, A. (2015). "Product services for a resource-efficient and circular economy - a review." Journal of Cleaner Production, 97, 76-91).

Vihola, J. and Edelman, H. (2016), "Life-Cycle Economics of Rentable Prefabricated School Facility Units in Municipal Real Estate Procurement" in Proceedings of the CIB World Buildings Congress, May 2016, Tampere, Finland, Tampere University of Technology.

Quale, J., Eckelman, M. J., Williams, K. W., Sloditskie, G., and Zimmerman, J. B. (2012) "Construction Matters - Comparing Environmental Impacts of Building Modular and Conventional Homes in the United States". Journal of Industrial Ecology, 16(2). 


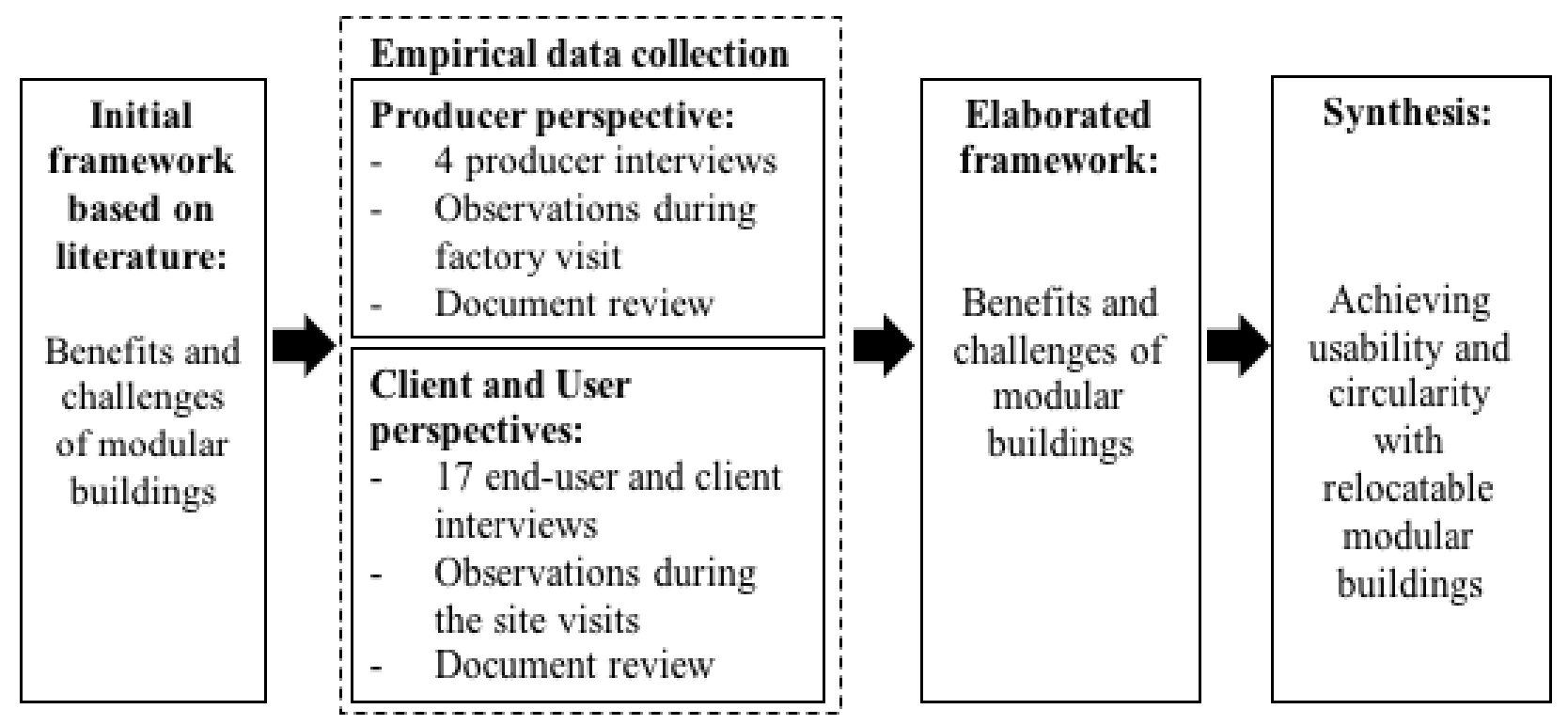

Figure 1 Research design 


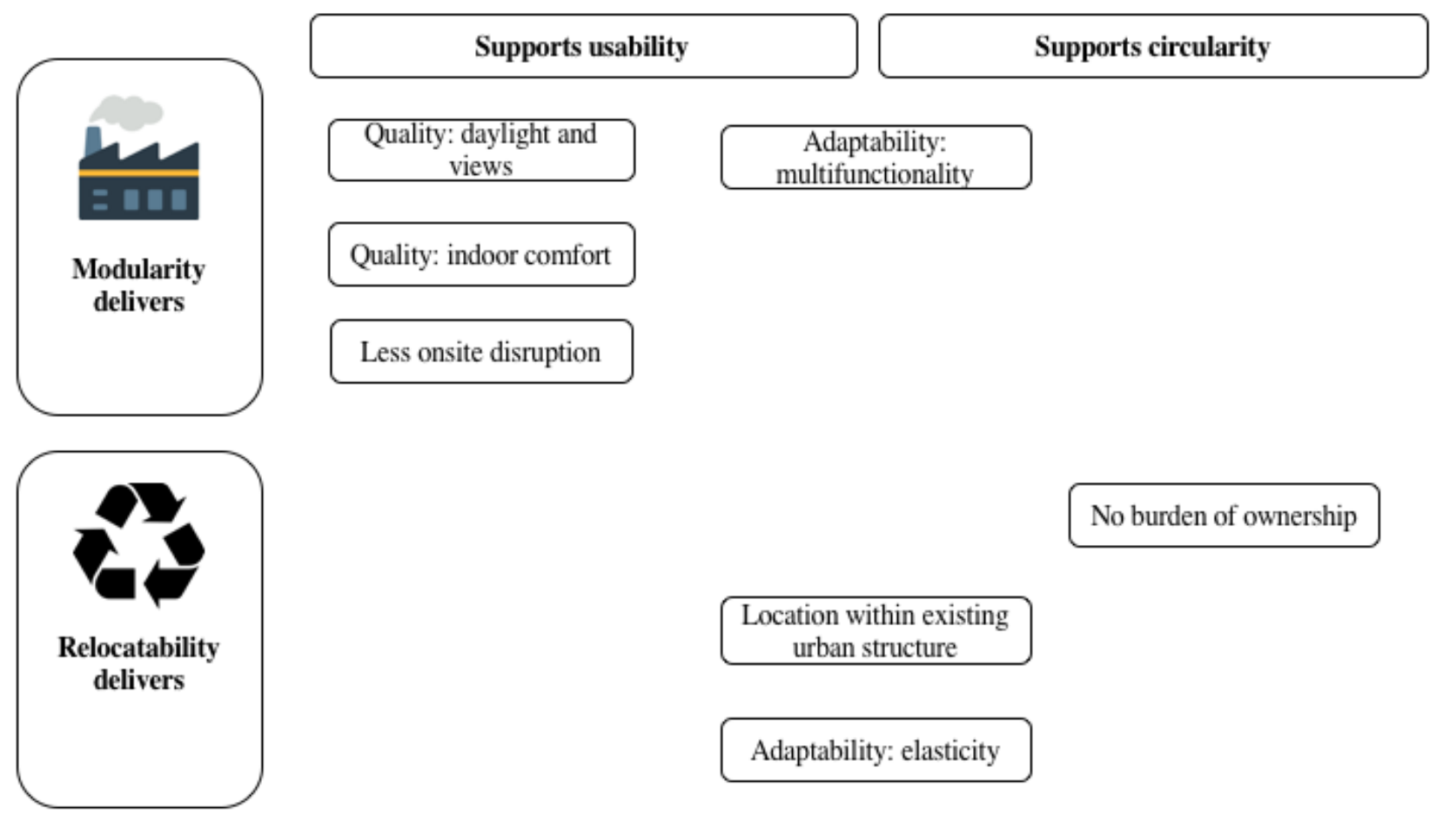


Table 1 Key characteristics of the cases

\begin{tabular}{lccc}
\hline Case A & Case B & Case C \\
\hline Site & Hospital Campus & Care Home & Healthcare Center \\
\hline Location & $\begin{array}{c}\text { Hyvinkää, mid- } \\
\text { sized city in } \\
\text { Southern Finland }\end{array}$ & $\begin{array}{c}\text { Helsinki, capital city, } \\
\text { Southern Finland }\end{array}$ & $\begin{array}{c}\text { Lappeenranta, mid- } \\
\text { sized city in Eastern } \\
\text { Finland }\end{array}$ \\
\hline Year developed & 2012 & early 2000's & 2015 \\
\hline Amenities and functions & $\begin{array}{c}\text { Offices, consulting } \\
\text { rooms, imaging } \\
\text { services }\end{array}$ & $\begin{array}{c}\text { Elderly housing with } \\
\text { communal kitchen and } \\
\text { living space }\end{array}$ & $\begin{array}{c}\text { Offices, consulting } \\
\text { rooms }\end{array}$ \\
\hline Lease period & 5 years & n/a (site owned) & 5 years \\
\hline Site visit and interviews & December 2016 & December 2016 & March 2017 \\
\hline
\end{tabular}


Table 2 Summary of the interviews

\begin{tabular}{ll}
\hline Type of interview & Number of interviews \\
\hline Producer interviews & 4 \\
\hline Client interviews & Case A: 1 \\
& Case B: 2 \\
& Case C: 1 \\
\hline User interviews & Case A: 4 \\
& Case B: 2 \\
& Case C: 7 \\
\hline In total & $\mathbf{2 1}$ interviews \\
\hline
\end{tabular}


Table 3 Initial framework for modular buildings

\begin{tabular}{|c|c|c|c|c|c|c|c|c|c|c|c|c|c|}
\hline & 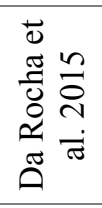 & 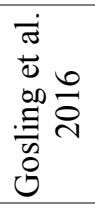 & 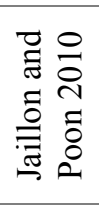 & 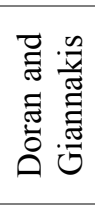 & 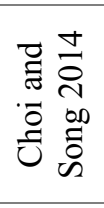 & 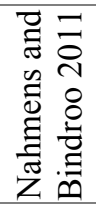 & 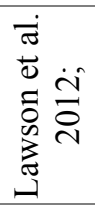 & 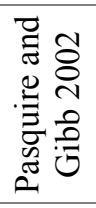 & 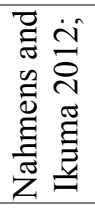 & 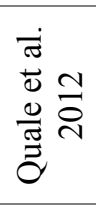 & 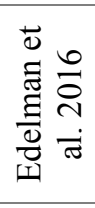 & 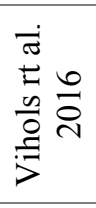 & $\begin{array}{l}\overrightarrow{0} \\
\stackrel{0}{0} \frac{1}{0} \\
\frac{0}{2} \\
\frac{1}{0} \frac{1}{0} \\
\frac{0}{0}\end{array}$ \\
\hline \multicolumn{14}{|l|}{ BENEFITS } \\
\hline Rapidity & $\mathrm{x}$ & & & & & & & & & & & & $\mathrm{x}$ \\
\hline Quality & & $\mathrm{x}$ & $\mathrm{x}$ & & $\mathrm{x}$ & $\mathrm{x}$ & $\mathrm{x}$ & $\mathrm{x}$ & & $\mathrm{x}$ & & & \\
\hline Sustainability & & & & & & & $\mathrm{x}$ & & $\mathrm{x}$ & $\mathrm{x}$ & & & \\
\hline Adaptability & & & & & & & & & & & $\mathrm{x}$ & $\mathrm{x}$ & $\mathrm{x}$ \\
\hline $\begin{array}{l}\text { No burden of } \\
\text { ownership }\end{array}$ & & & & & & & & & & & & $\mathrm{x}$ & \\
\hline \multicolumn{14}{|c|}{ CHALLENGES } \\
\hline Rigid design & $\mathrm{X}$ & $\mathrm{x}$ & & & & & & & & & & & \\
\hline $\begin{array}{l}\text { Dimensional } \\
\text { restrictions }\end{array}$ & & $\mathrm{x}$ & & $\mathrm{x}$ & & & & & & & & & \\
\hline Poor image & & $\mathrm{x}$ & & & & & & & & & $\mathrm{x}$ & & \\
\hline
\end{tabular}


Table 4 Framework for modular buildings

\begin{tabular}{|c|c|c|}
\hline $\begin{array}{l}\text { Discussed } \\
\text { in }\end{array}$ & $\begin{array}{l}\text { Discussed in } \\
\text { Producer }\end{array}$ & $\begin{array}{c}\text { Discussed in Client and User } \\
\text { interviews }\end{array}$ \\
\hline
\end{tabular}

$\begin{array}{lll}\text { A } & \text { B } & \text { C }\end{array}$

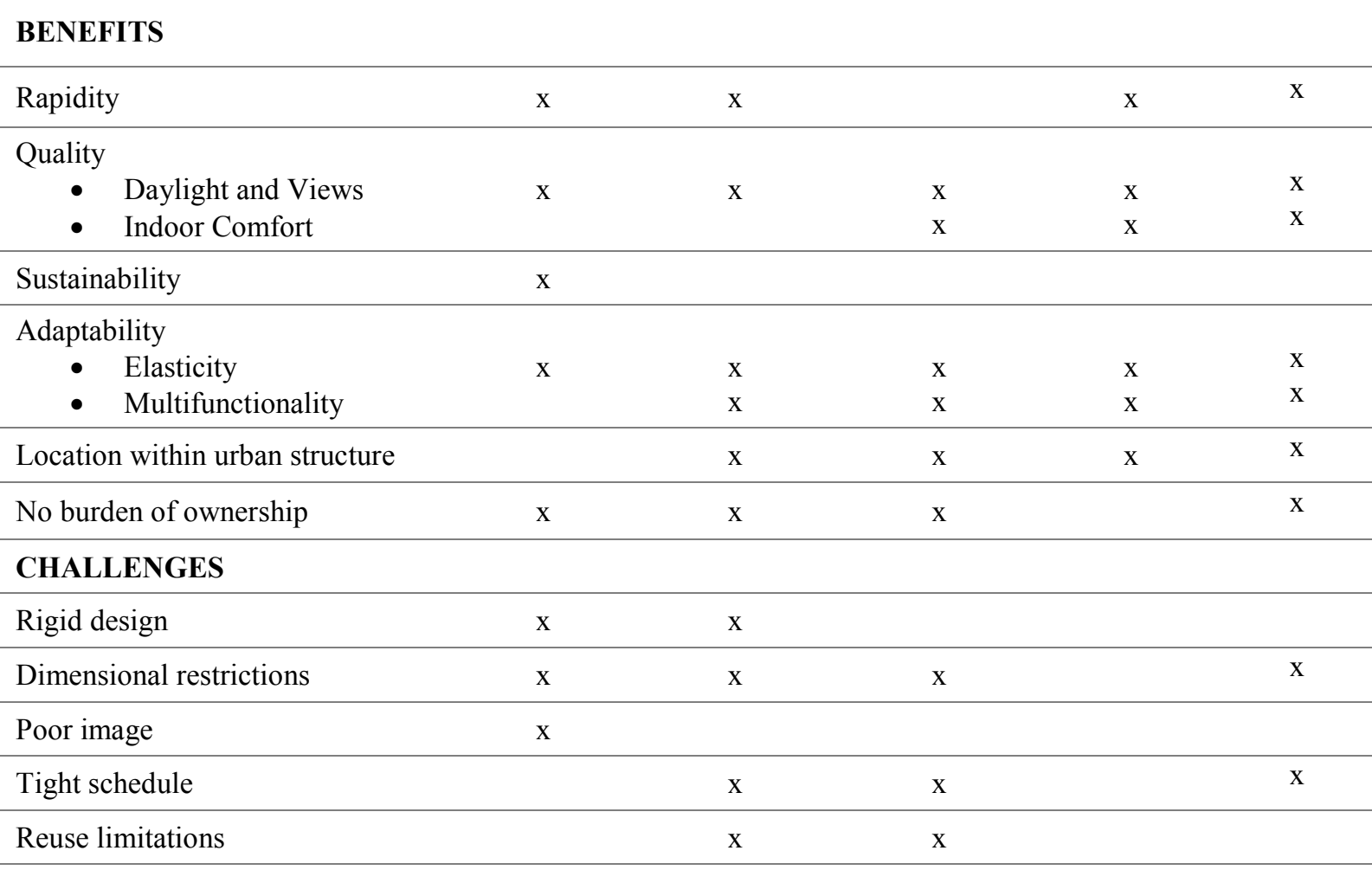




\section{APPENDIX 1}

\begin{tabular}{|c|c|c|c|c|}
\hline & Informant & Role in organization & Case & Interview length (min.) \\
\hline 1 & Producer 1 & Chief Operating Officer & $\mathrm{n} / \mathrm{a}$ & 61 \\
\hline 2 & Producer 2 & Sales Director & $\mathrm{n} / \mathrm{a}$ & 66 \\
\hline 3 & Producer 3 & Head Designer & $\mathrm{n} / \mathrm{a}$ & 54 \\
\hline 4 & Producer 4 & Chief executive officer & $\mathrm{n} / \mathrm{a}$ & 32 \\
\hline 5 & Client 1 & Real Estate Manager & A & 56 \\
\hline 6 & User 1 & Nurse/IT Support & A & 47 \\
\hline 7 & User 2 & Head Nurse & A & 47 \\
\hline 8 & User 3 & Chief Physician & A & 46 \\
\hline 9 & User 4 & Radiologic Nurse & A & 33 \\
\hline 10 & Client 2 & Architect & $\mathrm{B}$ & 90 \\
\hline 11 & Client 3 & Architect & $\mathrm{B}$ & 36 \\
\hline 12 & User 5 & Nurse & $\mathrm{B}$ & 58 \\
\hline 13 & User 6 & Nurse & $\mathrm{B}$ & 52 \\
\hline 14 & Client 4 & Real Estate Manager & $\mathrm{C}$ & 82 (telephone interview) \\
\hline 15 & User 7 & Nurse & $\mathrm{C}$ & 55 \\
\hline 16 & User 8 & Nurse & $\mathrm{C}$ & 55 \\
\hline 17 & User 9 & Nurse & $\mathrm{C}$ & 55 \\
\hline 18 & User 10 & Nurse & $\mathrm{C}$ & 19 \\
\hline 19 & User 11 & Nurse & $\mathrm{C}$ & 40 \\
\hline 20 & User 12 & Nurse & $\mathrm{C}$ & 40 \\
\hline 21 & User 13 & Nurse & $\mathrm{C}$ & 62 \\
\hline
\end{tabular}

